THE INTERNATIONAL

REVIEW OF RESEARCH IN

OPEN AND DISTANCE LEARNING

\title{
Determining the Feasibility of an E-Portfolio Application in a Distance Education Teaching Practice Course
}
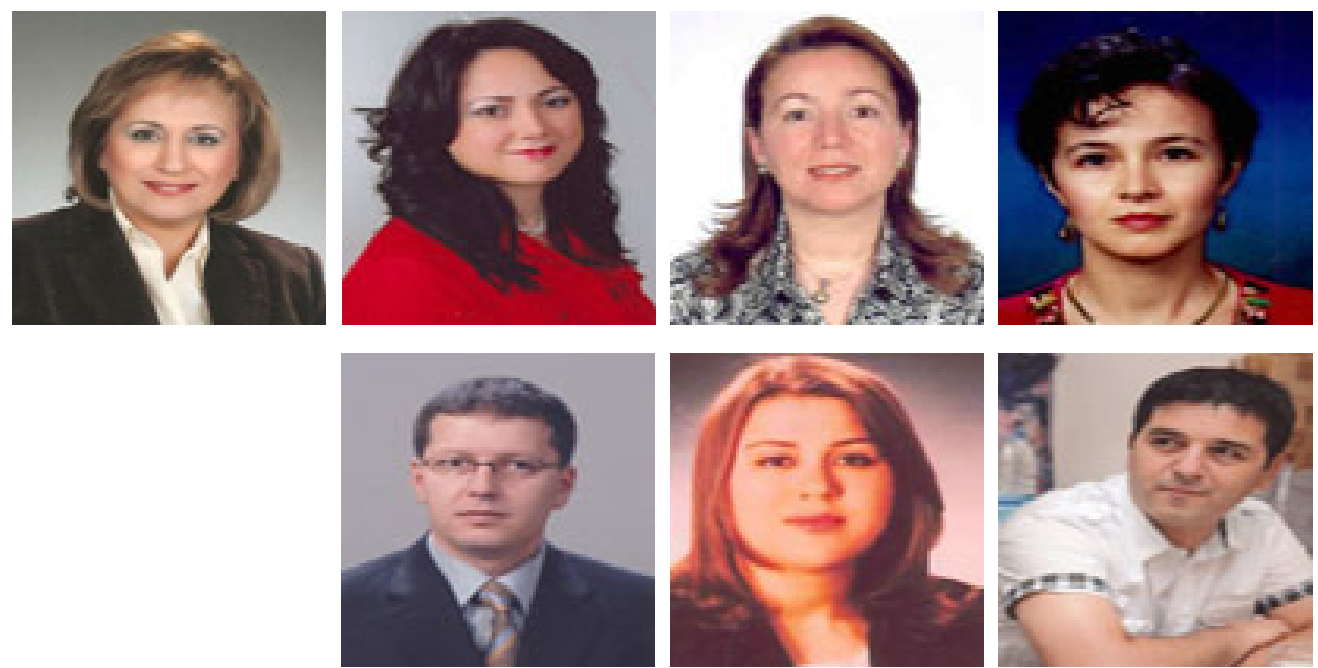

Ilknur Kecik, Belgin Aydin, Nurhan Sakar, Mine Dikdere, Sinan Aydın, and Ilknur Yuksel Anadolu University, Turkey

Mustafa Caner

Akdeniz University, Turkey

\section{Abstract}

In this study we aim to conduct a complete evaluation of the e-portfolio application in the distance teaching practice course that is part of the Distance English Language Teacher (DELT) program at Anadolu University from the perspective of three groups: university supervisors, preservice teachers, and cooperating teachers. Using a survey on the needs of preservice teachers and how well these were met according to the three groups' perspectives, we gathered qualitative and quantitative data on the feasibility of the e-portfolio application. Our analysis of the findings revealed that all three groups agreed about the needs of preservice teachers. And despite some minor variance in the perspectives of each group, we determined that e-portfolio applications can meet the majority of the planning, teaching, and reflection needs in the teaching process. We offer suggestions to improve eportfolio applications so they will better meet preservice teachers' needs.

Keywords: Distance education; interactive learning environments; adult learning; teaching practice 


\section{Introduction}

Teaching practice is an important phase of teacher education that provides opportunities for preservice teachers to reflect on their developing teaching philosophies and put them into action. This process helps preservice teachers to bridge the gap between theory and practice, to step into the professional teaching environment by sharing, cooperating, and collaborating with their more experienced peers, and to observe seasoned teachers in the classroom (McIntyre, Byrd, \& Foxx, 1996; Darling-Hammond \& Baratz-Snowden, 2007; Simpson, 2006).

This process includes three groups, preservice teachers, cooperating teachers, and university supervisors, who each have unique roles: Preservice teachers take the role of student teachers, the cooperating teachers act as models and mentors in the classroom, and university supervisors provide the necessary guidance and direction for preservice teachers (Goldsberry, 1998; Jonson, 2002; Wang \& Odell, 2002). The significance of such supervision in this process has been explained by Darling-Hammond and Baratz-Snowden (2007). They argued that when preservice teachers are well supervised, they are better able to connect theory to practice, more readily develop teaching skills, and are more confident.

A pioneering project developed by the Massachusetts Institute of Technology, which provides freely available teaching materials on a Web site, is one example of the opportunities online education systems offer. These systems have received considerable attention because they enhance interactivity and connectedness (Perraton, 2010). As a result, teacher education programs have begun embracing various web-based distance learning models to allow teachers to pursue additional education and professional growth experiences (Frey, 2008; Aldridge, Fraser, \& Ntuli, 2009; Ludlow \& Brannan, 1999; Beattie, Spooner, Jordan, Algozzine, \& Spooner, 2002). These models have provided new instructional tools, such as asynchronous web support through emails or discussion lists and forums and synchronous teleconferencing or videoconferencing, especially in circumstances where students have a greater need for guidance and supervision.

The importance of communication between the three groups involved in teacher education is evident at the School of Education at Seattle University (Roddy, 1999) and the University of Houston (Pierson \& McNeil, 2000), which used networked learning communities of lecturers, associate teachers, and students to enrich the field experience of student teachers. Likewise, an Australian study (Ballantyne \& Mylonas, 2001) pinpointed the three-way partnership between the associate teacher, lecturer, and student, showing how the use of online material and discussion set within a mentor model might help bridge the gap between the institution and remote field experience sites by involving mentor teachers, lecturers, and students in online discussion. In another study, Jung, Galyon-Keramidas, Collins, and Ludlow (2006) investigated the effectiveness of online or interactive video delivery on preservice teachers' professional development. Their findings showed that the observation and feedback provided through online video conferences satisfied the preservice teachers and contributed to their professional development. Likewise, Young and Lewis (2008) approved of the satisfaction and positive attitudes preservice teachers showed when their 
placements in distance education were supported with online programs.

Integrating a number of web-based and computer-based applications, electronic portfolios (e-portfolios) can serve as an instructional tool in the field of distance teacher education. Many believe e-portfolio applications have the potential to document each individual student's learning history, and thus they are accepted as a valuable tool for self-regulated learning, planning, self-directed learning, and setting learning goals (Imhof \& Picard, 2009; Gibson \& Barrett, 2003). As Barrett (2011) emphasized, the real value of e-portfolios is found in the student's reflection and learning, not just the collection of his or her work. E-portfolios offer opportunities for reflection on the self-regulated mode of individualized learning, as proponents of constructivist theories have posited (Gibson \& Barrett, 2003; Baumgartner, 2005). Further, e-portfolios encourage competencies and standard orientation in teacher education and help new teachers convey their personality and professionalism (Campbell, Cignetti, Melenyzer, Nettles, \& Wyman, 2004; Imhof \& Picard, 2009). They provide a context for discussion, review, and feedback from instructors, teachers, and colleagues. Hence, e-portfolios enable students' personal and professional growth and lifelong learning in distance education (Genç-Kumtepe, 2009; Lin, 2008; Frey, 2008).

E-portfolios help university instructors, cooperating teachers, and preservice teachers (the three groups of teacher education) to both engage in the process and move beyond the borders of traditional distance education (Simpson, 2006; Lin, 2008; Genç-Kumtepe, 2009). Further, Frey (2008) underlined that by using an online e-portfolio application, three main sources of support that are crucial for the development of students' teaching competencies, peer, instructor, and local school support, can be integrated into the teaching practice process. Collaborative resonance, which Cochran-Smith (as cited in Özköse-Bıyı, 2008) claimed was the most effective school-university relationship, can be established with an e-portfolio application. Such a relationship produces a richer environment, integrating all three groups. For preservice teachers, university supervisors can provide connections to cooperating teachers in schools through different applications such as discussions, seminars, and joint planning (Özköse-Bıyık, 2008). Moseley and Ramsay (2005) stated that both experienced and preservice teachers need to experience the joy of collaborative discussion, dialogue, critique, and research since such peer collaboration and mentoring can add value to the e-portfolio process. The e-portfolio is a tool for facilitating collaboration to bridge the interaction gap among the three groups, which is a crucial problem in teacher training via distance education (Beck, Livne, \& Bear, 2005; Knapczyk, Hew, \& Frey, 2005).

In order to catch up with these innovations in technology and distance education, the eportfolio has been recently applied in Turkey, particularly to teacher distance education programs. Although there is a paucity of research about this application, there are some pioneering studies exploring its use and impact. For instance, Koçoglu (2008) conducted a descriptive study on the views of preservice teachers of English as a Foreign Language (EFL) about the role of e-portfolios in their professional growth. In a similar vein, Koçoglu, Akyel, and Ercetin (2008) studied the improving effect of portfolio development on the reflective thinking ability of Turkish preservice teachers. Moreover, Genç-Kumtepe (2009) explored the strength of the e-portfolio as an assessment tool and looked at its motivational 
and cognitive benefits for preservice teachers in an early childhood distance teacher education program. Consistent with studies in the literature (Lin, 2008; Herner-Patnode \& Lee, 2009), Genç-Kumtepe (2009) found that the e-portfolio application provided students with an opportunity to revisit and revise their performance based on multiple feedback sources from certain points in time and expand their skills and knowledge. Further, Caner's (2009) PhD study of preservice teachers in a Turkish university English language teaching program revealed that including web support and interactive discussion boards enhanced the effectiveness of teaching practices. He claimed that through the interactive context, preservice teachers could receive helpful feedback on their lesson plans and teaching performance from both their supervisors and peers. Furthermore, Caner stated that the use of discussion boards in such circumstances might help participants to develop the capacity to think reflectively about their performance.

Overall, the studies to date have agreed on the promise of applying e-portfolio applications in teacher education since they can enhance the interactions between the three groups involved and help student teachers develop reflective practices. Based on these findings, an increasing number of colleges and universities all over the world now endeavor to develop both undergraduate and alternative online teacher preparation programs (Huss, 2007).

In a similar vein, Anadolu University, an institution conducting pioneering research for distance education in Turkey, has started to embed the online e-portfolio program into teaching practice courses in the Distance English Language Teacher Education (DELT) program. Gradually enriching the online component with new technologies, course planners hope to provide preservice teachers in different cities all over the country with interactive supervision.

Since the e-portfolio program in teacher education is a growing trend all over the world, examining how these applications are used in different cultures and different modes and a thorough evaluation of them will contribute to the literature about the integration of online technology in teacher education. Moreover, researchers recognize that understanding the voices of the three groups involved in the process leads to greater program efficiency and improved practices. Some researchers have expressed concern that most e-portfolio implementation does not consider the needs and views of the student users (Butler, 2010). Addressing their needs and including their perspectives is necessary to enhance their engagement with the e-portfolio (Tosh, Light, Fleming, \& Haywood, 2005). Thus, in our study we aim to describe the e-portfolio application for the teaching practice course in the DELT program and to evaluate its feasibility according to the perceptions of the three groups involved.

In line with the aims of the study, we first explain the e-portfolio application in the DELT program and then pose the following research questions.

1. At the beginning of the program, what were the needs of the preservice teachers during teaching practice from their own perspective and those of the cooperating teachers and university supervisors? 
2. From the perspectives of preservice teachers, cooperating teachers, and university supervisors, to what extent did the e-portfolio program meet these needs?

3. Were there any differences between perceived needs and those actually met for each participating group?

\section{The E-Portfolio Application in the DELT Program}

The DELT program is a four-year undergraduate degree; the university provides face-toface courses during the first two years in eight different city centers and in the third and fourth years delivers courses through distance education facilities.

The Teaching Practice course is one of the skill-based courses offered in the fourth year of the DELT program. The course has a 25-week syllabus, with 10 weeks devoted to micro teaching and 15 to macro teaching. During their fourth year, preservice teachers in the DELT program are given the chance to complete their teaching practice in any Turkish city. For the micro teaching component, they are required to observe cooperating teachers and the class they have chosen for a period of time then they must prepare a lesson plan for a 15-20-minute activity and teach it in the classroom environment. For the macro teaching component, preservice teachers prepare a plan for a whole lesson (40-45 minutes in duration) and teach this as well.

Instructors in the DELT program began using the e-portfolio application to facilitate the teaching practice process at the beginning of the 2009-2010 academic year. With this application, students can interact with their university supervisors and cooperating teachers. As a result, a network is established among all participants, thereby reducing preservice teacher isolation and increasing academic support.

The preservice teachers enrolled in the teaching practice course can access the e-portfolio application Web page (see http://eportfolio.iolp.anadolu.edu.tr) using a password-protected interface that was developed by staff at Anadolu University. The Web site includes the e-portfolios of preservice teachers with their lesson plans; instructor feedback; selfreflection reports; a forum where all three groups can discuss course-related subjects; and sections for announcements, technical questions, guidelines, the teaching practice handbook in e-book format (PDF), sample lesson videos, grading rubrics, and useful links. Figure 1 shows the home page of the e-portfolio application. 


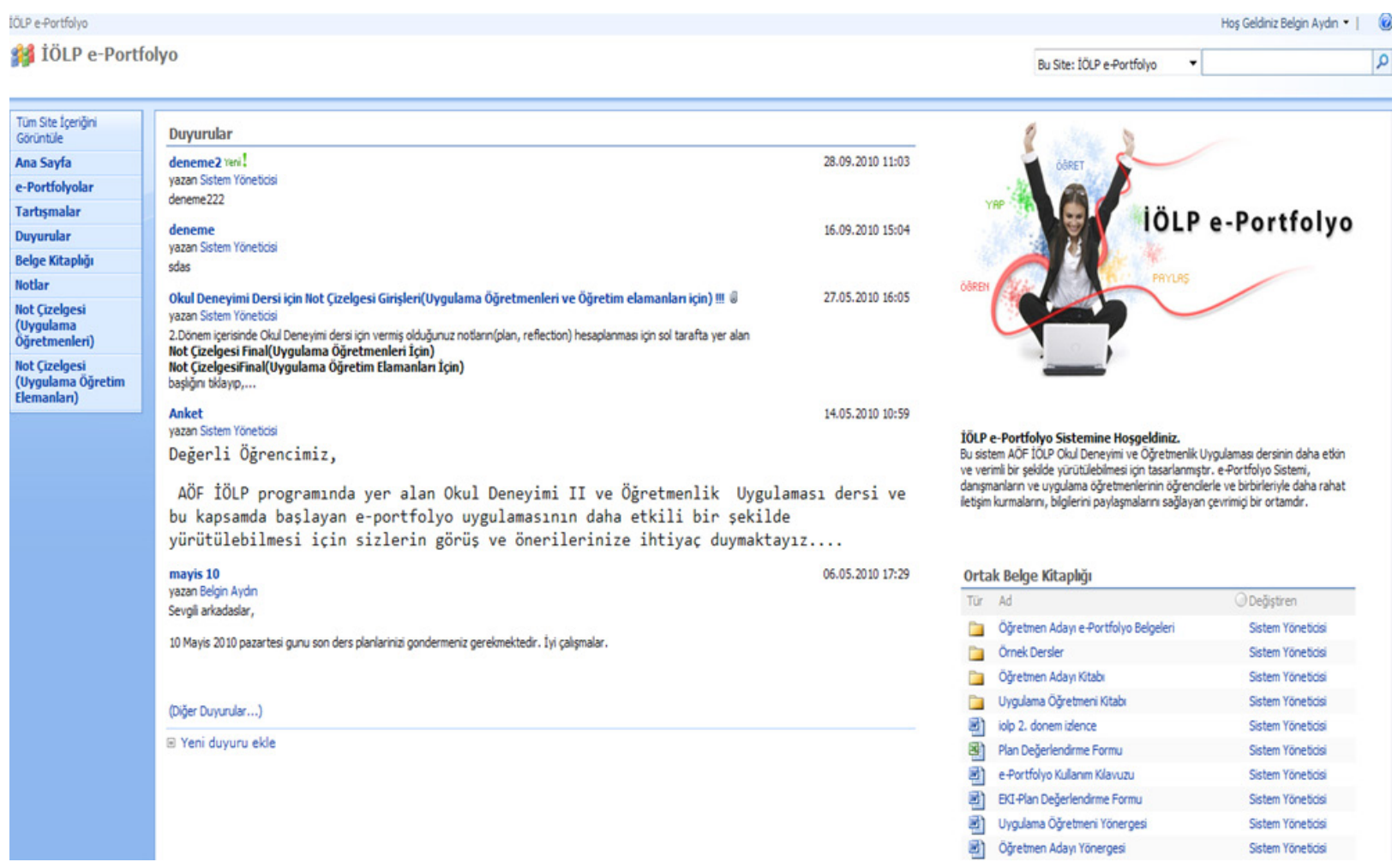

Figure 1. Home page of e-portfolio application used in the DELT Program.

Before the faculty implemented the e-portfolio application, a sample video on how to use it was prepared and uploaded to the Web site for all three groups to access. A discussion board reserved for any technical problems was inserted and the users were encouraged to ask for help to solve any issues they had while using the system. With these two components, the information technology skills of the participants were addressed.

On the e-portfolio Web page, preservice teachers were given personal space for their portfolios. Every six to eight preservice teachers were clustered to form a "mini discourse community" (Freidus, 2002, p. 75) in which university supervisors, cooperating teachers, and other peers could interact and provide feedback. To facilitate the lesson preparation process for preservice teachers and allow the university supervisors to effectively review the teaching practice process, the preservice teachers in the DELT program are asked to prepare their lesson plans prior to their teaching performance and upload them to their personal portfolios within the system. Both cooperating teachers and university supervisors give feedback on these plans, and the other preservice teachers within the same discourse community are able to see both the lesson plans and the feedback. After considering the feedback received from both cooperating teachers and supervisors and making the necessary changes, preservice teachers implement their final lesson plans in the real classroom and then write reflections on their experience soon after. Figure 2 shows a sample lesson plan, with feedback from the university supervisors. 


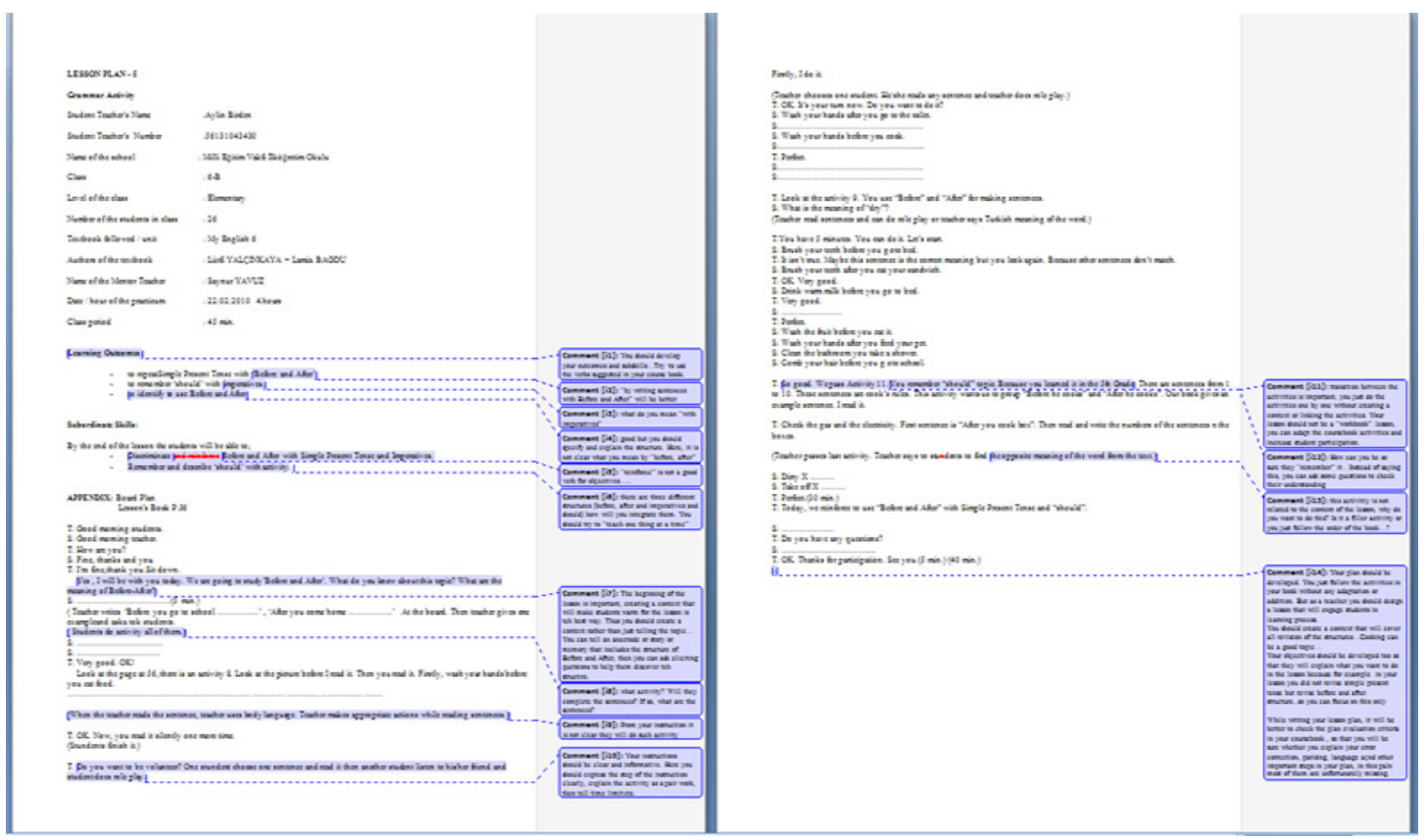

Figure 2. A sample lesson plan that was given feedback by university supervisors.

Incorporating the advice from cooperating teachers (onsite) and university supervisors (online), the preservice teachers in the DELT program have the chance to get feedback about their teaching plan and performance through the e-portfolio application. Moreover, the application offers an interactive platform for all group members to discuss and share important issues regarding teaching practice.

Working from the premise that a comprehensive evaluation of the application provides a greater chance to improve and enhance its benefits, for this study we evaluated the feasibility of an e-portfolio application from the perspectives of the active participants within the system.

In the following section, we present the research design of the study and our findings, with the support of related literature.

\section{Evaluation of the E-Portfolio Application in the DELT Program}

In line with the second aim of our study, we have conducted a summative evaluation of the distance education teaching course supported with the e-portfolio application at the DELT program. As Gibson and Barret (2003) stated, e-portfolios used as part of a program evaluation provide the opportunity to collect data about both program objectives and learners. Thus we examined the perspectives the three groups involved in the teaching practice had about the e-portfolio application to evaluate its feasibility.

\section{Method}

We designed the present study using a survey that integrates both qualitative and quanti- 
tative methods. Qualitative data served to provide a broader impression of the e-portfolio application, and quantitative data gave an in-depth analysis of the perspectives the three groups had of the application.

\section{Participants}

Study participants consisted of the preservice teachers $(n=914)$, university supervisors ( $n$ $=125)$, and cooperating teachers $(n=259)$ who used the e-portfolio application from the teaching practice course in the DELT program for the 2009-2010 academic year. Everyone in the three groups was asked to complete an online survey available on the home page. Out of 914 preservice teachers enrolled in the distance education teaching practice course, 59 voluntarily completed the survey. In a similar vein, so did 198 out of 259 cooperating teachers, and 94 out of 125 university supervisors. Thus, using a convenience sampling technique, 350 participants' perspectives on the e-portfolio system were included in the study.

\section{Instrument}

We developed an e-portfolio application survey as the data collection instrument to identify the needs of the preservice teachers during their teaching practice process and to determine whether these needs were met by the application from the perspectives of the three groups.

While developing the survey, we created a question pool reviewing the related literature and referring to the teaching practice evaluation rubric (Kecik, 2010; Kecik \& Aydın, 2009) used in the DELT program. The first draft of the survey included 80 items and was then examined by an expert committee for content and construct validity. After taking the expert committee's comments into account, the final version of the survey was prepared. The final Survey on E-Portfolio Application consisted of 48 items in two parts. The first part included items focusing on the preservice teachers' perceived needs during the teaching practice process and to what extent these needs were met with the e-portfolio application's support. These needs and how well they were met were measured on a 5-point Likert scale, ranging from 1 (Always), to 5 (Never). They were grouped into three main categories: planning (1-20), teaching (21-40), and reflection (41-48), divided according to the requirements of each teaching stage as explained in the teaching practice course textbook (Kecik \& Aydın, 2009). Open-ended questions were also included, allowing participants to provide more detailed opinions on the e-portfolio application.

\section{Data Collection and Analysis}

After the data were collected online, the quantitative data obtained from the first part of the survey (the needs assessment part) were analyzed using descriptive statistics and presented as means, standard deviation values, and frequencies. While evaluating the means, an ( $n$ - 1)/ $n$ formula was applied to determine the standard opinion ranges, which were $1-1.79$ (always); $1.80-2.59$ (mostly); $2.60-3.39$ (neutral); $3.40-4.19$ (sometimes); and 4.20 - 5.00 (never). Additionally, $t$-tests and one-way ANOVA tests were employed for both between- and within-group comparisons. Conversely, the qualitative data collected from the open-ended questions in the second part of the survey were analyzed using content analysis; two independent researchers first assigned codes after examining the whole data 
set, and then the codes were compared and the themes encompassing them defined.

\section{Results and Discussion}

The way e-portfolios are used within teacher education varies. For the processes of critical reflection and collaborative discussion to be authentically integrated into e-portfolio use, the application should be carefully planned in alignment with teacher education program philosophies, conceptual frameworks, and learning outcomes (Lamount, 2007). The perspectives of the three groups within the teacher education program are valuable resources to evaluate whether e-portfolio applications could satisfy user needs. In this study, we evaluated the perspectives of the three groups regarding the e-portfolio application based on this premise. In the following sections, we present the findings of the survey with reference to each research question.

\section{The Perceived Needs of the Three Groups Using the E-Portfolio}

For the first research question, "What are the needs of preservice teachers using the eportfolio during practice teaching from the perspectives of the preservice teachers, cooperating teachers, and supervisors?" we analyzed the first part of the survey, and the results are shown in Table 1.

Table 1

Perceived Needs of the Three Groups Using the E-Portfolio

\begin{tabular}{l|ll|ll|lll} 
& \multicolumn{2}{|l|}{ Preservice } & \multicolumn{2}{|l|}{ Supervisor } & \multicolumn{2}{l}{ Cooperating teacher } \\
Perceived needs & $n=58$ & & $n=94$ & & $n=198$ & \\
\cline { 2 - 7 } & & & & & & \\
& Mean & $S D$ & Mean & $S D$ & Mean & $S D$ \\
\hline Planning & 2.2345 & .91934 & 2.0718 & 1.01249 & 2.3194 & .77061 \\
\hline Teaching & 2.1836 & .99769 & 2.1489 & 1.01682 & 2.3331 & .81259 \\
\hline Reflection & & & & & & & \\
\hline
\end{tabular}


As Table 1 shows, in spite of the slight differences, all participants expressed very similar perceptions of preservice teachers' needs. The mean scores of all three groups ranged from 2.03, the lowest, to 2.33, the highest belonging to the "mostly" category for all the stages of teaching. That is, the participants agreed that the items listed in the survey were mostly needed by preservice teachers.

When we consider the teaching stages separately, we can see that although there were no obvious differences among the mean values of the three groups, the needs at the planning stage were emphasized by the supervisors (mean 2.07) more than the other two groups. In addition, regarding the teaching and reflection stages, both university supervisors and preservice teachers stated that there were more needs than the cooperating teachers did. We applied a one-way ANOVA test to identify whether the differences in the mean values of the participants were significant or not, and our findings are shown in Table 2.

Table 2

The Differences in Perceptions of Needs during Teaching Practice Supported with an EPortfolio Application

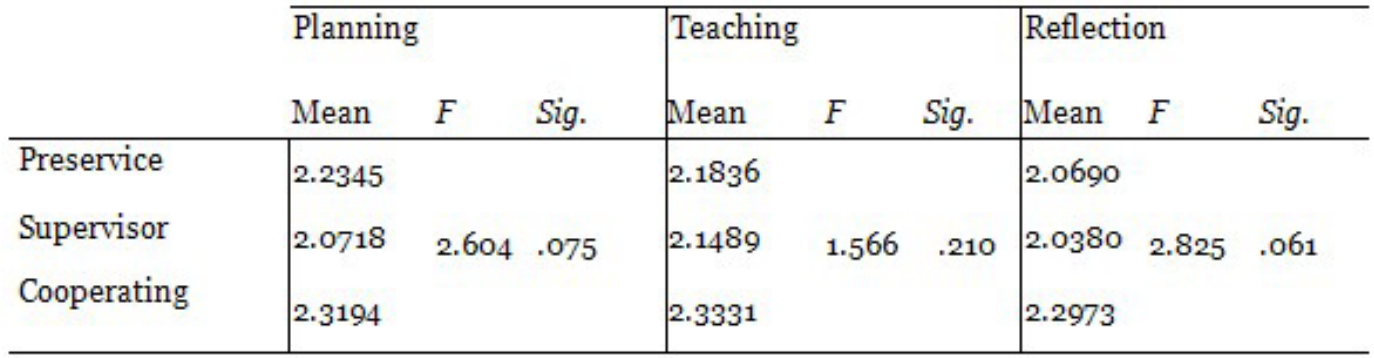

Table 2 shows that the ANOVA test results revealed no statistically significant differences in the needs of preservice teachers perceived by each group. That is, all three groups thought that preservice teachers had similar levels of need for the e-portfolio in the planning, teaching, and reflection stages of the teaching process. This finding suggests that the teaching experience process and its needs were perceived in similar ways by the three groups.

When the qualitative data were analyzed, "getting effective feedback from the cooperating teachers while planning" was identified as the most needed aspect of planning for preservice and cooperating teachers. Conversely, "writing the goal and sub-skills of the lesson accurately and clearly on the lesson plans" was thought to be the greatest need by the university supervisors. For instance, one of the university supervisors stated, "I could not teach two of my students how to write learning outcomes and sub-skills. I corrected them each time, gave feedback patiently ... they continued to write almost similar outcomes without any improvement" (US-10). Another supervisor made a similar point: "the biggest problem is writing the outcomes and sub-skill[s]. While their book has explanations about these, pre-service teachers cannot state them efficiently." (US-8) 
Regarding needs during the teaching stage, "using time effectively during teaching practice" (item 39) was the most commonly perceived need among preservice teachers. On the contrary, "enabling students' active participation while checking the activity" (item 28) was emphasized the most by supervisors and "encouraging students' active participation during the activity" (item 27) by the cooperating teachers. One of the preservice teachers (S1) stated, "I cannot be sure whether my lesson plan is too long or short for 40 minutes," focusing on his need to manage time effectively. For the reflection stage, the preservice and cooperating teachers agreed that the most important need was "getting effective postsession feedback from cooperating teacher" (item 45). However, according to the supervisors, preservice teachers required "reflecting on the students' learning difficulties in the class" the most (item 43) while reflecting on their teaching. In addition to these needs, all three groups agreed that the preservice teachers need "writing self-reflection on all teaching stages" (item 41).

To conclude, all three groups of participants agreed that preservice teachers had similar needs while planning, teaching, and reflecting on their teaching. Nevertheless, their perceptions differed in some of the subcategories. The reason for these differences in emphasis might be due to the different expectations of the groups. For example, while university supervisors focused on the importance of determining the outcomes of a lesson during the planning stage or involving students in the lesson while teaching, for preservice teachers, getting feedback about their lesson plans or their application was more important. The strength of e-portfolios within a teacher education program is their ability to place more responsibility for learning and personal growth in the hands of the student. In particular, eportfolios offer more opportunity for students to highlight their strengths and growth over

time. They also offer the potential for the student teacher to document a broader range of attributes, rather than simply meeting learning outcomes or professional standards.

\section{How Well Perceived Needs Were Met by Using the E-Portfolio}

The second research question asked how well the perceived needs were met according to the three groups. The findings are presented in Table 3. 
Table 3

The Differences in Perceptions about How Well Perceived Needs Were Met during a Teaching Practice Course Supported with an E-Portfolio Application

\begin{tabular}{l|cc|cc|cc}
\multirow{2}{*}{$\begin{array}{l}\text { Accomplishment } \\
\text { levels }\end{array}$} & \multicolumn{2}{|c|}{ Preservice } & \multicolumn{2}{c|}{ Supervisor } & \multicolumn{2}{c}{$\begin{array}{c}\text { Cooperating } \\
\text { teacher }\end{array}$} \\
\cline { 2 - 7 } & Mean & $S D$ & Mean & $S D$ & Mean & $S D$ \\
\hline Planning & 2.5198 & 1.01298 & 2.6378 & .78084 & 2.3376 & .68151 \\
\hline Teaching & 2.5086 & 1.05884 & 2.7814 & .71022 & 2.3053 & .66728 \\
\hline Reflection & 2.3750 & 1.02384 & 3.0598 & .73774 & 2.1711 & .76019
\end{tabular}

Table 3 indicates that all the mentioned needs at all teaching stages were mostly accomplished, according to the preservice and cooperating teachers.

The university supervisors, however, thought that while preservice teachers' needs at the planning and teaching stages were mostly met, their needs at the reflection stage were not met as well as the other two stages by the e-portfolio application. In order to examine whether the differences in the mean values were significant or not, we applied a one-way ANOVA test. The results of the comparisons are illustrated in Table 4.

Table 4

Comparing Perceptions of Accomplishment Levels

\begin{tabular}{l|lll|lll|lll} 
& \multicolumn{3}{|c|}{ Planning } & \multicolumn{3}{c|}{ Teaching } & \multicolumn{3}{c}{ Reflection } \\
\cline { 2 - 10 } & Mean & $F$ & Sig. & Mean & $F$ & Sig. & Mean & $F$ & Sig. \\
\hline Preservice & 2.5198 & & & 2.5086 & & 2.3750 & \\
\hline Supervisors & 2.6378 & 5.117 & $.006^{*}$ & 2.7814 & 12.731 & $.000^{*}$ & 3.0620 & 39.236 & .000* $^{*}$ \\
\hline Cooperating & 2.3376 & & & 2.3053 & & & 2.1731 & &
\end{tabular}

*significant at .05 level

As Table 4 indicates, the obtained $P$ values for each teaching stage were smaller than the significance level of .05, which revealed significant differences among the groups in terms of the met needs. That is, preservice teachers, cooperating teachers, and university supervisors indicated different opinions about all three stages of the teaching process.

In order to identify which group indicated these different responses we applied Tukey's 
HSD test, and the results indicated the university supervisors and cooperating teachers were the source. The mean values suggested that university supervisors were in the negative pool while cooperating teachers were in the positive. University supervisors were pessimistic and thought that the e-portfolio application could not meet the needs of students within the teaching practice process satisfactorily. The underlying reason for this might be their ambitious goals and higher expectations for teacher education. Some of the university supervisors could not adapt to the asynchronous e-portfolio use, so they were not satisfied with using only the written medium because they believed that face-to-face interaction should be included to enhance the effectiveness of the whole teaching practice process. In addition, their unfamiliarity with the secondary and primary school context, where the actual teaching practice takes place, might have triggered this pessimistic stance.

When the findings were revisited on the basis of each item, we detected that for the planning stage, "getting feedback from cooperating teachers while planning" (item 19), the most commonly perceived need, was also the one most commonly met according to preservice teachers. These examples from the preservice teachers indicate their opinions about how well their needs were met and their satisfaction with the feedback received through e-portfolio application.

Getting feedback both from the cooperating teachers and the supervisors helps me to see my weaknesses and strengths. As the time passes, I like this application more. (S-20)

I could prepare my future plans more easily with the help of feedback I got. (S-50)

These findings and the preservice teachers' ideas are consistent with the literature. Knapcyzk et al. (2005) emphasized the value of consistent, task-oriented, and timely feedback provided by online mentors (in this case, supervisors or cooperating teachers). With the advance of computer technology, the interaction between the three groups in the teaching practice process moves beyond geographical locations and into a/synchronous interactions. The feedback exchange at the heart of teaching practice, as emphasized by the findings of this study, is now feasible. Study participants also underlined the value of feedback and its contribution to their professional growth.

Regarding how well perceived needs were met, for preservice teachers the need "drawing students' attention in the class" (item 22) was the most well met, for cooperating teachers it was the need of "having effective interaction with the students in the class" (item 26), and for the university supervisors, the need for "giving clear instructions" (item 23) was best met.

It should be emphasized that these findings also point to the advantage of e-portfolio applications informing the preservice teachers' teaching performance in an actual class in 
harmony with their needs and accomplishment levels. The e-portfolio application is an interactive platform where cooperating teachers can upload the preservice teachers' performance evaluations frequently and give feedback about their performance if necessary. The university supervisors can also review these evaluations and interact with the cooperating teachers or preservice teachers on such teaching practice issues.

For the reflection stage, "getting effective feedback from cooperating teachers on the actual teaching" (item 45) was the most well-met need according to preservice and cooperating teachers. We expected this finding since cooperating teachers are available and onsite for face-to-face reflection about student performances during the process. Thus, the preservice teachers considered their need for feedback from cooperating teachers to have been met. This feedback provided them with other reflections on their performance. This finding also implies the preservice teachers' need for university supervisors' feedback on their actual teaching. Although university supervisors are included in the process actively with the eportfolio, there is still a need to involve them in the postsession feedback about preservice teachers' teaching performance. We suggest uploading the video records of the preservice teachers' teaching practice into the system and enabling the university supervisors to give feedback as well. Enriching the feedback on teaching practice in this way would help the preservice teachers improve their teaching skills and foster their interaction with class supervisors.

For the university supervisors, "writing a rationale" (item 48) was the most well-met need at the reflection stage. To write rationales, preservice teachers must think about their goals and how to accomplish them in the lesson. Thus they start to reflect on their teaching and evaluate their approaches. In the e-portfolio application, preservice teachers write their rationales for a larger audience-cooperative teachers, university supervisors, and peers. They also have the chance to revise other rationales and they can be motivated to develop their rationales by reflecting on past experiences. On this point, the e-portfolio engages the students in self-reflection, reviewing goals periodically (Lin, 2008).

However, the three groups' perceptions about how well the preservice teacher needs were met for "writing self-reflection on all teaching stages" (item 41) differed: While the preservice teachers and cooperating teachers believed that this need was mostly met by the e-portfolio application, the supervisors remained neutral. In the e-portfolio application, the preservice teachers were asked to write a critical reflection after each teaching practice, and supervisors and cooperating teachers were to evaluate these reflective papers. While the preservice teachers and cooperating teachers seemed to be satisfied with the opportunity for self-reflection that the e-portfolio application offers, the university supervisors expected more from both the preservice teachers and the application. The supervisors neutral stance could be interpreted as their expectation for better reflections.

The findings on how well the reflection needs of the preservice teachers were met complied with the literature. That is, other researchers commonly agree that e-portfolios have the potential to enhance reflective thinking (Kocaoglu et al., 2008). Using e-portfolios, preservice teachers are stimulated to engage in reflective practice, to develop effective learning 
strategies, and to gain and review technology skills (Lin, 2008; Bataneih, Al-Karashneh, \& Al-Barakat, 2007).

In contrast, when we look at the unmet needs, we see that cooperating teachers felt preservice teachers were not very successful "reflecting on the students' learning difficulties in the class" (item 43). For the preservice teachers and university supervisors, "getting peer feedback on the actual teaching" (item 41) was not met as well as other needs by the application. By identifying such unmet needs, we consider how the e-portfolio application can be improved and developed as a more reflective tool.

\section{The Comparison of the Three Groups' Perceptions about Needs and How Well the Needs Were Actually Met}

To address the last research question, "Were there any differences between perceived needs and those actually met for each participating group?" we employed a $t$-test to the findings about the three groups' perceptions.

Table 5

The Comparison of Perceived and Met Needs in Terms of All Three Groups' Perspectives

\begin{tabular}{|c|c|c|c|c|c|c|c|c|c|c|c|c|c|}
\hline & & \multicolumn{4}{|c|}{ Preservice Teachers } & \multicolumn{4}{|c|}{ Cooperating teachers } & \multicolumn{4}{|c|}{ University supervisors } \\
\hline & & Mean & $t$ & $d f$ & Sig. & Mean & $t$ & $d f$ & Sig. & Mean & $t$ & $d f$ & Sig. \\
\hline \multirow[t]{2}{*}{ Planning } & Perceived needs & 2.2345 & \multirow[t]{2}{*}{-1.948} & \multirow{2}{*}{57} & \multirow{2}{*}{.056} & 2.3194 & \multirow[t]{2}{*}{-.279} & \multirow[t]{2}{*}{197} & \multirow[t]{2}{*}{.780} & 2.0718 & \multirow{2}{*}{-4.626} & \multirow{2}{*}{93} & \multirow{2}{*}{$.000 *$} \\
\hline & Accomplishment & 2.5198 & & & & 2.3376 & & & & 2.6378 & & & \\
\hline \multirow[t]{2}{*}{ Teaching } & Perceived needs & 2.1836 & \multirow[t]{2}{*}{-2.207} & \multirow[t]{2}{*}{57} & \multirow{2}{*}{$.031 *$} & 2.3331 & \multirow[t]{2}{*}{.407} & \multirow[t]{2}{*}{197} & \multirow[t]{2}{*}{.684} & 2.1489 & \multirow{2}{*}{-5.273} & \multirow{2}{*}{93} & \multirow{2}{*}{$.000 *$} \\
\hline & Accomplishment & 2.5086 & & & & 2.3053 & & & & 2.7814 & & & \\
\hline \multirow[t]{2}{*}{ Reflection } & Perceived needs & 2.0690 & \multirow[t]{2}{*}{-2.134} & \multirow[t]{2}{*}{57} & \multirow{2}{*}{$.037 *$} & 2.2955 & \multirow[t]{2}{*}{1864} & \multirow[t]{2}{*}{197} & \multirow[t]{2}{*}{.064} & 2.0359 & \multirow{2}{*}{-7.897} & \multirow{2}{*}{93} & \multirow{2}{*}{$.000 *$} \\
\hline & Accomplishment & 2.3750 & & & & 2.1711 & & & & 3.0598 & & & \\
\hline
\end{tabular}

*significant at .05 level

There was no difference between the perceived needs at the planning stage and how well they were met, while there was a significant difference between the perceived and met needs at the teaching and reflection stages. In other words, these findings indicated that the preservice teachers' needs at the planning stage were mostly met by the e-portfolio system. The preservice teachers thought that the e-portfolio application addressed their planning needs before they started the teaching process. However, their needs at the teaching and reflection stages were not met as well as they were for the planning stage. These findings also point to the necessity of including the university supervisors in the postobservational feedback sessions.

Moreover, the findings indicate that for the cooperating teachers, there was no difference between the perceived and met needs for all the stages of the teaching process. According to cooperating teachers, all the needs of preservice teachers were met by the e-portfolio 
system.

In contrast, for the university supervisors there were significant differences for all teaching stages. The university supervisors believed the e-portfolio application did not successfully meet the preservice teachers' needs during the planning, teaching, and reflection stages as much as it should have. They might have had higher expectations both for the preservice teachers and the e-portfolio application.

\section{Conclusion}

The main reason to use the e-portfolio application is to develop the effectiveness of teaching practice by including the third group, university supervisors, during the process, increasing the interaction opportunities among all the participants and providing immediate feedback to preservice teachers by creating a flexible learning environment. The aim of our study was to examine the feasibility of the e-portfolio system by reviewing the perceptions of the participants on the needs of the preservice teachers and how well these were met. The results indicated that the perceptions of the preservice teachers, cooperating teachers, and supervisors concerning the needs of preservice teachers using an e-portfolio were not different from one another. This similarity might suggest that all the participants perceived the process of teaching in terms of planning, teaching, and reflection stages similarly.

When these needs and how well they were met were considered, the university supervisors differed from the other groups, stating that the needs of the preservice teachers weren't satisfactorily met and further that students at the reflection stage of teaching require more guidance. Analysis of the data also revealed that while preservice teachers' needs (as they defined them) during the planning stage were mostly met by the e-portfolio system, the teaching and reflection needs were not met as well as needed. These results suggest the necessity of revising the application of the e-portfolio system in order to better address these perceived needs. Focusing on identifying and stating the objectives of lessons and making reflections for preservice teachers; giving more detailed and explicit feedback for the cooperating teachers; and helping the cooperating teachers, supervisors, and preservice teachers develop their skills in reflecting and giving feedback seem to be the essential aspects that need improvement.

Nevertheless, the results of this study are similar to those found by Ballantyne and Mylonas (2001), Caner (2009), Kocoglu, Akyel, and Ercetin (2008), and Lin (2008). Having the opportunity to interact with cooperating teachers and supervisors and get feedback for what the preservice teachers do facilitates their professional development, and the e-portfolio application provides a valuable medium that leads to collaboration, self-development both as a teacher and a social partner, construction or reconstruction of knowledge, and development of autonomy.

Our findings indicate that the e-portfolio system enabled university supervisors to be actively involved in the distance teaching practice process from the beginning. 
Users appreciated the e-portfolio and perceived it as advantageous because it provided

- an interactive platform for all the participants,

- the opportunity for instructors to provide immediate feedback for the preservice teachers, and

- the ability to store and review the feedback without any time limitations.

However, our study also revealed a need to improve the e-portfolio system. The three groups' perceptions of which needs that were not met shed light on aspects that must be improved. These results indicate

- the necessity of in-service education for the three groups, particularly on how to effectively use the e-portfolio application; and

- the necessity of further guidance for preservice teachers about the reflection stage of the teaching process. 


\section{References}

Aldridge, J., Fraser, B., \& Ntuli, S. (2009). Utilizing learning environment assessments to improve teaching practices among in-service teachers undertaking a distance education programme. South African Journal of Education, 29 (2), 147-170.

Ballantyne, R., \& Mylonas, A. (2001). Improving student learning during "remote" schoolbased teaching experiences using a flexible delivery of teacher, mentor, and student preparation programmes. Asia-Pacific Journal of Teacher Education, 29(3), 263-273.

Barrett, H. (2011). Balancing the two faces of e-portfolios ( $2^{\text {nd }}$ ed.) British Columbia: Ministry of Education, Innovations in Education. Retrived from http://electronicportfolios.org/balance/balancingarticle2.pd.

Bataineh, R.F., Al-Karasneh, S.M., Al-Barakat, A. A., \& Bataineh, R. F. (2007). Jordanian preservice teachers' perceptions of the portfolio as a reflective learning tool. AsiaPacific Journal of Teacher Education, 35(4), 435-454.

Baumgartner, P. (April, 2005). Competence-based education with weblogs and e-portfolios: A challenge for developing a new learning culture. Paper presented at a conference on e-Portfolios Salzburg, Germany. Retrieved from http://www.peter. baumgartner.name/paper-de/competence-based-education-with-weblogs-andeportfolios- a-challenge-for-developing-a-new-learning-culture.

Beattie, J., Spooner, F., Jordan, L., Algozzine, B., \& Spooner, M. (2002). Evaluating instruction in distance learning classes. Teacher Education and Special Education, 25(2), 124-32.

Beck, R. J., Livne, N. L., \& Bear, S. L. (2005). Teachers' self-assessment of the effects of formative and summative electronic portfolios on professional development. $\mathrm{Eu}$ ropean Journal of Teacher Education, 28, 221-244.

Campbell, D. M., Cignetti, P. B., Melenyzer, B. J., Nettles, D. H., \& Wyman, R. M. (2004). How to develop a professional portfolio. A manual for teachers. New York: Pearson.

Caner, M. (2009). A study of a blended learning model for teaching practice course in a pre- service English Language Teacher Education program (Doctoral dissertation). Anadolu University, Graduate School of Educational Sciences, Turkey.

Darling Hammond, L., \& Baratz Snowden, J. (2007). A good teacher in every classroom: Preparing the highly qualified teachers our children deserve. Educational Horizons, 85(2), 111-132.

Frey, T. (2008). Determining the impact of online practicum facilitation for in-service 
teachers. Journal of Technology and Teacher Education, 16(2), 181-210.

Friedus, H. (2002). Teacher education faculty as supervisors/advisors/facilitators: Playing multiple roles in the construction of field work experiences. Teacher Education Quarterly, 29(2), 65-76.

Genç-Kumtepe, E. (June, 2009). Eportfolio system for preservice distance teacher education program: An alternative assessment story, from boxes through eContainers. Paper presented at the 23rd ICDE World Conference on Open Learning and Distance Education, Maastricht, Holland.

Gibson, D. \& Barrett, H. (2003). Directions in electronic portfolio development. Contemporary Issues in Technology and Teacher Education, 2(4), 559-576.

Goldsberry, L. F. (1998). Teacher involvement in supervision. In G. R. Firth \& E. F. Pajak (Eds.), Handbook of research in school supervision (pp. 428-462). New York: Macmillan.

Herner-Patnode, L. M., \& Lee, H.-J. (2009). A capstone experience for pre-service teachers: Building a web-based portfolio. Educational Technology \& Society, 12(2), 101-110.

Huss. J. A. (2007). Web-based teacher preparation programs and elementary education: Will principals hire these teachers? Electronic Journal for the Integration of Technology in Education, 6, 43-54.

Imhof, M., \& Picard, C. (2009). Views on using e-portfolios in teacher education. Teaching and Teacher Education, 25, 149-154.

Jonson, K. F. (2002). Being an effective mentor. Thousand Oaks, CA: Corwin Press.

Jung, L. A., Galyon-Keramidas, C., Collins, B. C., \& Ludlow, B. L. (2006). Distance education strategies to support practica in rural settings. Rural Special Education Quarterly, 25(2), 18-24.

Kecik, İ., \& Aydın, B. (Eds.) (2009). Okul Deneyimi ve Öğretmenlik Uygulaması Öğretmen Adayı Kitabı. Anadolu Üniversitesi Yayınları No:200o. Eskişehir.

Knapczyk, D. R., Hew, K. F., Frey, T. J., \& Wall-Marencik, W. (2005). Evaluation of online mentoring of practicum for limited licensed teachers. Teacher Education and Special Education, 28(3/4), 207-220.

Kocoglu, Z., Akyel, A., \& Ercetin, G. (2008). Pen/paper and electronic portfolios: An effective tool for developing reflective thinking of Turkish EFL student teachers? Mediterranean Journal of Educational Studies, 13(1), 1-24.

Lamount, M. (2007). What are the features of e-portfolio implementation that can enhance learning and promote self-regulation? Retrieved from the Web site of the 
European Institute for ELearning, EIfEL: www.eife-l.org.

Lin, Q. (2008). Preservice teachers' learning experiences of constructing e-portfolios online. Internet and Higher Education, 11(3-4), 194-200.

Ludlow, B. L., \& Brannan, S. A. (1999). Distance education programs preparing personnel for rural areas: Current practices, emerging trends, and future directions. Rural Special Education Quarterly, 18(3 \& 4), 5-21.

McIntyre, D. J., Byrd, D. M., \& Foxx, S. M. (1996). Field and laboratory experiences. In J. Sikula, T. J. Buttery, \& E. Guyton (Eds.), Handbook of research on teacher education ( $2^{\text {nd }}$ ed., pp. 171-193). New York: Macmillan.

Moseley, C., \& Ramsay, S. (2005). Teaching portfolios in teacher education: Effects of program-wide mentoring on elementary pre-service teachers' perceptions. Current Issues in Education Online, 8(23). Retrieved from http://cie.ed.asu.edu/volume8/ number23/.

Özkose-Biylk, C. (2008). Student teachers' experiences in the distance English language teacher Education Program (DELTEP) in Anadolu University, Turkey. Paper presented at the annual meeting of the Northeastern Educational Research Association, Rocky Hill, Connecticut. Retrieved from http://www.albany.edu/ c0166416/ Eportfolio/documents/ETAP777 ResearchProject.pdf

Perraton, H. (2010). Teacher education: The role of open and distance learning. Vancouver, Canada: Commonwealth of Learning. Retrieved from http://www.col.org/ PublicationDocuments/pub_TeacherEd_Role_ODL.pdf

Pierson, M. E., \& McNeil, S. (2000). Preservice technology integration through collaborative action communities. Contemporary Issues in Technology and Teacher Education, 1(1), 189-199.

Roddy, M. (1999). Using the Internet to unite student teaching and teacher education. Journal of Teaching and Teacher Education, 7(3), 257-267.

Simpson, M. (2006). Field experience in distance-delivered initial teacher education programmes. Journal of Technology and Teacher Education, 14(2), 241-254.

Tosh, D., Light, T. P., Fleming, K., \& Haywood, J. (2005). Engagement with electronic portfolios: Challenges from the student perspective. Canadian Journal of Learning and Technology, 31(3), 89-110.

Wang, J., \& Odell, S. (2002). Mentored learning to teach according to standards-based reform: A critical review. Review of Educational Research, 72(3), 481-546.

Young, A., \& Lewis, W. (2008). Teacher education programmes delivered at a distance: An 
examination of distance student perceptions. Teaching and Teacher Education, 24(3), 601-609.

\section{Athabasca University $\mathbf{a}$}

(c) (1)

BY 